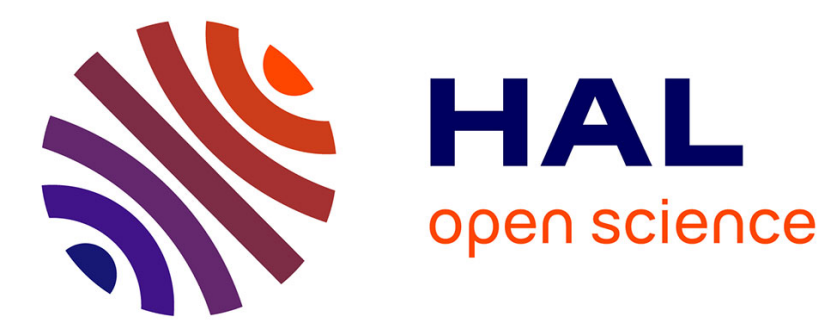

\title{
Drug-induced retroperitoneal fibrosis: a case/non-case study in the French PharmacoVigilance Database
}

Diana Brasselet, Laurent Chouchana, Thierry Vial, Marlène Damin-Pernik, Bénédicte Lebrun-Vignes

\section{- To cite this version:}

Diana Brasselet, Laurent Chouchana, Thierry Vial, Marlène Damin-Pernik, Bénédicte LebrunVignes. Drug-induced retroperitoneal fibrosis: a case/non-case study in the French PharmacoVigilance Database. Expert Opinion on Drug Safety, 2020, 19 (7), pp.903-914. 10.1080/14740338.2020.1766022 . hal-02946433

\section{HAL Id: hal-02946433 \\ https://hal.sorbonne-universite.fr/hal-02946433}

Submitted on 17 Nov 2020

HAL is a multi-disciplinary open access archive for the deposit and dissemination of scientific research documents, whether they are published or not. The documents may come from teaching and research institutions in France or abroad, or from public or private research centers.
L'archive ouverte pluridisciplinaire HAL, est destinée au dépôt et à la diffusion de documents scientifiques de niveau recherche, publiés ou non, émanant des établissements d'enseignement et de recherche français ou étrangers, des laboratoires publics ou privés. 


\title{
Title: Drug-induced retroperitoneal fibrosis: a case/non-case study in the French PharmacoVigilance Database
}

\author{
Diana Brasselet, \\ University Hospital Pitié Salpêtrière, Regional Pharmacovigilance Center, Paris, France
}

Laurent Chouchana,

AP-HP, Cochin Hospital, Regional Pharmacovigilance Center, Paris, France

Thierry Vial,

Hospices Civils de Lyon, Centre Régional de Pharmacovigilance, Lyon, France

Marlène Damin-Pernik,

Centre Hospitalier Universitaire de Saint-Etienne, Regional Pharmacovigilance Center Saint-Etienne, RhôneAlpes, France

Bénédicte Lebrun-Vignes,

University Hospital Pitié Salpêtrière, Regional Pharmacovigilance Center, Paris, France

\section{Data Sharing}

The data that support the findings of this study are available from the corresponding author upon reasonable request.

\section{Keywords}

Adverse Drug Reactions

Pharmacovigilance

Pharmacoepidemiology

Drug safety

\section{Abbreviations}

ADR: adverse drug reaction

CI: confidence interval

CT: computed tomography

DEA: derivatives of ergot alkaloids

FPVD: French PharmacoVigilance Database

MedDra: Medical Dictionary for Drug Regulatory Activities

MRI: magnetic resonance imaging

RCPVs: Regional Centers of Pharmacovigilance

RF: renal failure

ROR: reporting odds ratio

RPF: retroperitoneal fibrosis

\section{Abstract}

Background: The potential role of drugs in the onset of retroperitoneal fibrosis (RPF) is poorly understood.

Aim: To identify drugs that may cause RPF.

Method: We used the case/non-case method in the French PharmacoVigilance Database (FPVD).

Results: Among the 722992 reports recorded, we identified 73 cases of RPF. 67\% were men and th median age was 60 years (range 26-87). In these 73 cases, 176 drugs were 'suspect'. Derivatives of Informationrgotsalkaloids (DEA) presented the most significant association with RPF. To a lesser extent, significant associations are found with many drugs used in cardiology —eg, beta-blockers, platelet 
(TNF- $\alpha$ antagonist) or not known (some hypnotics, antiepileptic drugs, antipsychotics, anxiolytics, and antidepressants) to induce such an adverse drug reaction (ADR). Finally, these data could contribute to realize prospective studies to confirm these signals.

\section{Introduction}

Retroperitoneal fibrosis (RPF) is a rare disease characterized by a fibro-inflammatory tissue, which usually surrounds the abdominal aorta and/or the iliac arteries and extends into the retroperitoneum to envelop neighboring structures - eg, ureters (1). RPF is generally idiopathic.

The clinical manifestations of RPF are nonspecific. Manifestations can be localized —eg, pain, deep vein thrombosis, leg edema (by compressive effects of the fibro-inflammatory tissue on inferior vena cava), urinary disorders until acute renal failure (by ureters compression) and/or systemic (related to the immune nature of the disease) - eg, anorexia, fatigue, fever (1-3). Because of the non-specific clinical manifestations, there is often an important delay between the first symptoms occurrence and RPF diagnosis. This explains why the diagnosis is often realized at an advanced stage of RPF especially in the context of end-stage renal failure (1). Also, these clinical manifestations are insufficient to make the diagnosis of RPF. The diagnosis is made based on computed tomography (CT) or magnetic resonance imaging (MRI) (2). Biopsy and histological examination of the retroperitoneal tissue are necessary when the mass presents atypical localizations - eg pelvic, peripancreatic and/or when the clinical signs and laboratory values suggest an infectious or malignant disease to exclude these aetiologies. Apart from surgical management such as ureterolysis, steroids are often used to treat idiopathic RPF as first-line treatment (4), also other practices in patients with relapsing RPF-eg, association with methotrexate (5), other immunosuppressants or tamoxifen — are sometimes realized.

The pathogenesis of idiopathic RPF is unclear and probably multifactorial: environmental factors (asbestos, tobacco) $(6,7)$, systemic autoimmune process especially in the context of IgG4-related disease (8) and although thought to be small there would exist a genetic component (9). Idiopathic RPF accounts for more than two thirds of the cases of RPF. The remaining third being secondary to infections, cancer, trauma, surgery, radiotherapy or drug intake $(1,10)$.

Iatrogenic RPF is poorly understood except for derivatives of ergot alkaloids (DEA) which represent the most common drugs associated with this adverse drug reaction (ADR). Indeed, no clear data are available about its prevalence and incidence and iatrogenic RPF is described mostly through case reports in the literature. Thus, the aim of this study was to investigate associations between drugs and reports of RPF, using the case/non-case method in the French PharmacoVigilance Database (FPVD).

\section{Methods}

\subsection{Case/non-case method}

The case/non-case method measures disproportionality between the combination of a drug and a particular ADR, here RPF, in a pharmacovigilance database (11-13). Cases are reports corresponding to the ADR of interest (here RPF) and non-cases are all reports of ADRs other than the ADR of interest. The method permits a comparison of drug exposure among cases and non-cases. The strength of the association between drug exposure and the occurrence of the ADR of interest is evaluated by the calculation of an ADR reporting odds ratio (ROR) with its 95\% confidence interval (CI).

\subsection{Source: the French PharmacoVigilance Database (FPVD)}

The French Pharmacovigilance system consists of a network of 31 regional pharmacovigilance centers (11). The FPVD was created in 1985 to record any reports of ADR spontaneously notified by health professionals and since 2011 also by patients. For each report, information about patient (age, gender, medical history) and drug intake are recorded in the FPVD. ADRs are coded according to the 
Medical Dictionary for Drug Regulatory Activities (MedDRA) (14). A causality assessment for each drug is performed using the french method ("Begaud" method) (15). Clinical details are summarized at the end of each report. Evolution can be updated later, after further investigations. Seriousness was defined as an ADR leading to death, hospitalization (or prolongation of hospitalization), persistent or significant disability or incapacity, being life-threatening or other medical justification (16).

\subsection{Selection of 'cases' and 'non-cases'}

As a first step, we identified all spontaneous reports registered between 1 January 1985 and 27 December 2017 under the MedDra terms « peritoneal and retroperitoneal fibrosis and adhesions » (High Level Term). All these reports were carefully reviewed by 2 pharmacovigilance specialists (DB, LC). Second, we included in the study only reports with imaging confirmed RPF (CT scan or MRI). When the report was not sufficiently informative or when another aetiology was finally found (oncological, infectious) according to the detailed summary of the clinical description, the case was not included in the analysis.

'Non-cases' were defined as all other reports (i.e. all other reports not defined as retroperitoneal fibrosis) recorded during the same period in the FPVD.

\subsection{Statistical analysis}

Collected data were compared between cases (reports defined as RPF) and non-cases. We calculated the ROR to compare the risk of drug exposure among cases and non-cases. The RORs are given with their $95 \% \mathrm{CI}(16)$.

\section{Results}

\subsection{Characteristics of cases}

Of the 722992 reports recorded in the FPVD between 1 January 1985 and 27 December 2017, 125 were reported as «peritoneal and retroperitoneal fibrosis and adhesions », 7 cases were excluded because another aetiology was finally found, 44 cases were excluded because of lack of information or RPF not confirmed by imaging and one duplicate has been identified. 73 reports were finally validated as RPF. Among them, $67 \%(\mathrm{~N}=49)$ were men. Median age was 60 years (mean: 59 years; min: 26 years; max: 87 years). Nearly half of the patients had a medical history of hypertension $(45.2 \% ; \mathrm{N}=33), 17.8 \%$ had dyslipidaemia $(\mathrm{N}=13)$ and $15.1 \%$ were diabetic $(\mathrm{N}=11) .28 .8 \%$ of the patients were diagnosed in a context of renal failure (RF), isolated RF or associated with lower limb damage or abdominal and/or low-back pain. A ureteral obstruction was objectified at imaging for $32.9 \%$ of patients and $6.8 \%$ had hydronephrosis. Among patients treated by antihypertensive drugs, $21 \%$ had ureteral obstruction. One patient had an aortic aneurysm and one patient had a fibrosis extended into the mediastinal zone (without details) (Table 1). Dosage of IgG4 was specified for only 4 patients: no elevation of IgG4 was found for 3 of them and one patient had a subnormal values. All cases were serious: $81 \%$ with hospitalization $(\mathrm{N}=59), 12 \%$ with "other medical justification" $(\mathrm{N}=9), 3 \%$ "persistent or significant disability or incapacity" $(\mathrm{N}=2), 3 \%$ were life-threatening $(\mathrm{N}=2)$ and one was fatal.

Among the 73 cases, 176 drugs were "suspect". Median delay to RPF occurrence was 2 years and 7 months (mean: 5 years and 4 months; min: 22 days; max: 33 years and 9 months). This delay has been calculated from the date of introduction of the suspected drugs. Modification in drug intake after RPF diagnosis was known for 143 suspected drugs: drug withdrawal $(\mathrm{N}=82)$, unchanged dosage $(\mathrm{N}=60)$, decreased dosage $(\mathrm{N}=1)$. RPF therapeutic management was specified for 29 cases: corticosteroids $(\mathrm{N}=27)$ and tamoxifen $(\mathrm{N}=2)$. Evolution was known for only 21 cases: death $(\mathrm{N}=1)$, RPF extension $(\mathrm{N}=2)$, RPF stability $(\mathrm{N}=6)$, incomplete $(\mathrm{N}=11)$ or complete $(\mathrm{N}=1)$ regression.

[Table 1] 


\subsection{Case/non-case comparison}

The case/non-case analysis included the 73 patients ("cases") and the 722867 reports ("noncases"). The 52 excluded cases were not included in the analysis. In the 73 cases, 176 drugs were defined as "suspect" (i.e. possibly associated with the occurrence of ADR whatever the level of imputability), with a mean of 2.4 drugs per case. Table 2 indicates the values of ROR between the occurrence of RPF and drug exposure in the FPVD. Derivatives of ergot alkaloids (DEA) presented the most significant association with RPF. To a lesser extent, significant association was found with many drugs used in cardiology - eg, beta-blockers, platelet antiaggregant, statins, antihypertensive drugs including inhibitors of the renin-angiotensin system and diuretics, drugs used in neuropsychiatry-eg, hypnotics, antiepileptic drugs, anxiolytics, antipsychotics, and antidepressants and with others therapeutics classeg TNF-alpha, antidiabetics... Concerning beta-blockers, when the indication was known, it was always hypertension except for one case where the indication was myocardial infarction with a probable heart failure.

\section{[Table 2]}

\section{Discussion}

As far as we know, this is the first large systematic study that investigates drugs involved in RPF and the characteristics of iatrogenic RPF through a pharmacovigilance database. Previously, RPF has been acknowledged mainly by case reports (Table 3). Our study suggests that, in usual medical practice, many drugs, not only DEA, can be suspected in RPF occurrence.

The case/non-case method is a relevant method for detecting associations between a rare adverse drug effect such as RPF and drug exposure in real conditions of use. This study presents some mandatory methodological drawbacks as with all other studies using a pharmacovigilance database - eg, underreporting $(17,18)$ and other biases detailed below. From a methodological point of view, our study is original compared with previous publications about iatrogenic RPF. It improve our knowledge about the circumstances of occurrence of this rare ADR in real clinical practice.

Epidemiological characteristics of iatrogenic RPF are not established in literature. Compared to patients with idiopathic RPF, the characteristics of our cases were similar in terms of age or sex ratio. Men are approximately affected twice as often as women by RPF $(1,19)$. The mean age is around 50-60 years $(1,19)$. Nearly half of our patients suffering from hypertension which corresponds to the proportion described by Estrade and al. (3). Hypertension in patients with RPF is probably of renal origin by a rise in renin release secondary to urinary tract obstruction or entrapment of the renal artery (20). The considerable delay between the suspected drug introduction and RPF diagnosis can be explained by the nonspecific clinical manifestations of the disease and by the slow chronic process of fibrosis. Lugosi and $a l$. found a mean delay between the first symptoms and the diagnosis of 258 days with extremes ranging from one to 1422 days (21). RPF evolution is variable: complete or partial regression, persistence or extension despite corticosteroid therapy $(3,21)$, which is found in our study.

We found a very important disproportionality signal with DEA that can be explained partly by a notoriety bias. Indeed, DEA including antiparkinsonian drugs, inhibitors of prolactin secretion and antimigraine drugs, is the pharmacological class most frequently associated with iatrogenic RPF in literature $(22,23)$ with a fibrotic risk widely described in valvular heart disease (24-26). The pharmacological explanation is that DEA induced activation of the 5-HT2B serotonin receptor, lead to fibroblast proliferation and increased extracellular matrix, including collagen and glycosaminoglycan $(25,27)$.

The association between beta-blockers and RPF is currently not well established. Various cases were published in the 70s-80s (28-30). Some authors suggested that beta-blockers were probably being used to treat hypertension associated with RPF rather than to induce directly RPF (31). Indeed, 
hypertension induced by RPF is probably diagnosed and treated by antihypertensive drugs before the underlying disease diagnose. The hypothesis of a protopathic bias (and also a notoriety bias, for the same reasons than DEA) could explain the important signal found with beta-blockers and especially because beta-blockers indication in our study is always hypertension excepting for one patient with a medical history of myocardial infarction and probable heart failure. However, in our study patients treated by antihypertensive drugs including beta-blockers were not more affected by ureteral obstruction. This doesn't support the protopathic bias hypothesis. A significant disproportionality was also found with other antihypertensive drugs - eg diuretics, agents acting on the renin-angiotensin system and lipid-modifying agents, platelet antiaggregants and antidiabetic drugs. Except for some cases described in the 70s-80s with prolonged treatment of an analgesic dose of aspirin (32) and a case reported with hydrochlorothiazide (33) there is no association between these drugs and RPF occurrence in literature. It's should be noted that benfluorex has a known risk of valvular lesions explained by 5-HT2B serotonin receptor activation by one of its metabolites, norfenfluramine. Lugosi and al. describe that near than half patients with RPF have at least two cardiovascular risk factors (21) that could explain the use of these drugs in patients with RPF even if the absence of a significant signal found with calcium antagonists limits this hypothesis.

According to current data available in the literature, the role of TNF- $\alpha$ antagonist in RPF genesis is not clear. Some cases are described, mainly with etanercept (34-36). Occurrence of a pathology for which a treatment is known to be effective called a paradoxical effect, has been notified for TNF- $\alpha$ antagonist - eg sarcoidosis (37), psoriasis, scleritis, uveitis, large-vessel vasculitis, and inflammatory bowel diseases. Lupus-like syndrome is also reported with these drugs. This dysregulation of the immune system induced by TNF- $\alpha$ antagonists could promote immune-mediated RPF occurrence. Less likely, RPF might be a manifestation of a systemic autoimmune or inflammatory disease (1) treated by TNF- $\alpha$ antagonist with therefore a possible indication bias. Moreover, we found a case of refractory RPF to combined glucocorticoid and methotrexate therapy treated effectively with infliximab (38).

A significant disproportionality was found with antihistamines drugs, ferrous sulfate and various drugs used in neuropsychiatry such as antipsychotics, antiepileptics, hypnotics, anxiolytics, and antidepressants. According to our knowledge, there is no association between these drugs and RPF in literature. It is therefore difficult to conclude about a new association between the occurrence of RPF and these drugs brought to light in this study or on the existence of unidentified biases. There is also no pharmacological explanation that could explain this signal. More generally about fibrotic risk, currently data shown that elevation of serotonin blood and/or synaptic cleft concentrations resulting from the pharmacological effects of antidepressant is not sufficient to increase the fibrotic risk and that 5-HT2B serotonin receptor stimulation seems to be the main factor (39). None of these drugs have a significant 5-HT2B agonist activity and further studies are needed to understand this signal.

Some authors in the 70s-80s suggested that excessive and prolonged consumption of analgesics (codeine, aspirin, phenacetin) could be associated with the occurrence of RPF (32). In our study, there is no significant signal found with analgesics apart from aspirin.

No significant signal was found with proton pump inhibitors, platinum salts or calcium antagonists.

\section{[Table 3]}

\section{Conclusion}

In conclusion, the association between RPF occurrence and drugs is difficult to establish because of a history of drug intake sometimes arduous to reconstitute due to late diagnosis and difficulty to conclude on the evolution at the suspected drug withdrawal (unsystematic regression of fibrosis or potentially related to corticosteroids efficacy). Despite the compulsory limits of the case/non-case study 
(confounding factors, underreporting...), these data represent a pharmacovigilance signal and can contribute to perform prospective studies in order to confirm these signals. A significant association has been found between various drugs and RPF reports. This concerns not only drugs known to be associated with this ADR (DEA) but also other drugs less known (TNF- $\alpha$ antagonist) or not known (some antipsychotics, antiepileptics, hypnotics, anxiolytics, and antidepressants) to induce such an ADR. Our results emphasize that, in clinical practice, a systematic anamnesis about drug intake should be performed in each aetiological research of RPF and especially because no aetiology is found for more than two-thirds of the cases of RPF.

\section{Declaration of interests}

All authors have no conflict of interest to disclose in relation to this study. 


\section{References}

1. Vaglio A, Salvarani C, Buzio C. Retroperitoneal fibrosis. Lancet Lond Engl. 21 janv 2006;367(9506):241-51.

- This is a general article about RPF detailing mechanisms probably involved in the pathogenesis of idiopathic RPF especially in the context of systemic autoimmune process.

2. Vaglio A, Maritati F. Idiopathic Retroperitoneal Fibrosis. J Am Soc Nephrol. juill 2016;27(7):1880-9.

3. Estrade V, Traxer O, Sibony M, et al. [Retroperitoneal fibrosis]. Ann Urol. févr 2004;38(1):3-13.

4. Vaglio A, Palmisano A, Alberici F, et al. Prednisone versus tamoxifen in patients with idiopathic retroperitoneal fibrosis: an open-label randomised controlled trial. Lancet Lond Engl. 23 juill 2011;378(9788):338-46.

5. Alberici F, Palmisano A, Urban ML, et al. Methotrexate plus prednisone in patients with relapsing idiopathic retroperitoneal fibrosis. Ann Rheum Dis. 1 sept 2013;72(9):1584-6.

6. Swartz RD. Retroperitoneal Fibrosis and Asbestosis-A Plausible Association? Am J Kidney Dis. mars 2015;65(3):378-80.

7. Goldoni M, Bonini S, Urban ML, et al. Asbestos and Smoking as Risk Factors for Idiopathic Retroperitoneal Fibrosis: A Case-Control Study. Ann Intern Med. 5 août 2014;161(3):181.

8. Rossi GM, Rocco R, Accorsi Buttini E, et al. Idiopathic retroperitoneal fibrosis and its overlap with IgG4-related disease. Intern Emerg Med. avr 2017;12(3):287-99.

9. Klein J, Sato A. The HLA System. N Engl J Med. 14 sept 2000;343(11):782-6.

10. Palmisano A, Vaglio A. Chronic periaortitis: a fibro-inflammatory disorder. Best Pract Res Clin Rheumatol. juin 2009;23(3):339-53.

11. Moore N, Noblet C, Kreft-Jais C, et al. [French pharmacovigilance database system: examples of utilisation]. Therapie. déc 1995;50(6):557-62.

12. Rochoy M, Zakhem-Stachera C, Béné J, et al. [Antidepressive agents and hyponatremia: A literature review and a case/non-case study in the French Pharmacovigilance database]. Therapie. oct 2018;73(5):389-98.

13. Montastruc G, Favreliere S, Sommet A, et al. Drugs and dilated cardiomyopathies: a case/noncase study in the French PharmacoVigilance Database. Br J Clin Pharmacol. mars 2010;69(3):287-94.

14. Brown EG, Wood L, Wood S. The medical dictionary for regulatory activities (MedDRA). Drug Saf. févr 1999;20(2):109-17.

15. Miremont-Salamé G, Théophile H, Haramburu F, et al. Causality assessment in pharmacovigilance: The French method and its successive updates. Therapie. avr 2016;71(2):179-86.

16. Ewans S. Statistics: analysis and presentation of safety data. 2004;301-28.

17. Hazell L, Shakir SAW. Under-reporting of adverse drug reactions : a systematic review. Drug Saf. 2006;29(5):385-96. 
18. Thiessard F, Roux E, Miremont-Salamé G, et al. Trends in spontaneous adverse drug reaction reports to the French pharmacovigilance system (1986-2001). Drug Saf. 2005;28(8):731-40.

19. Lioger B, Yahiaoui Y, Kahn J-E, et al. [Retroperitoneal fibrosis in adults: Main characteristics and relevance of the diagnostic procedures based on a retrospective multicenter study on 77 cases]. Rev Med Interne. juin 2016;37(6):387-93.

20. van Bommel EFH. Retroperitoneal fibrosis. Neth J Med. juill 2002;60(6):231-42.

21. Lugosi M, Sacré K, Lidove O, et al. [Long-term follow-up of a French cohort of retroperitoneal fibrosis]. Rev Med Interne. oct 2013;34(10):591-9.

22. Bilici A, Karadag B, Doventas A, et al. Retroperitoneal fibrosis caused by pergolide in a patient with Parkinson's disease. Neth J Med. nov 2004;62(10):389-92.

23. Shaunak S, Wilkins A, Pilling JB, et al. Pericardial, retroperitoneal, and pleural fibrosis induced by pergolide. J Neurol Neurosurg Psychiatry. janv 1999;66(1):79-81.

24. Antonini A, Poewe W. Fibrotic heart-valve reactions to dopamine-agonist treatment in Parkinson's disease. Lancet Neurol. sept 2007;6(9):826-9.

25. Zanettini R, Antonini A, Gatto G, et al. Valvular heart disease and the use of dopamine agonists for Parkinson's disease. N Engl J Med. 4 janv 2007;356(1):39-46.

26. Corvol J-C, Schüpbach M, Bonnet A-M, et al. [Pergolide associated valvulopathy: critical analysis of the literature and practical recommendations]. Rev Neurol. juill 2005;161(6-7):637-43.

27. Smith SA, Waggoner AD, de las Fuentes L, et al. Role of Serotoninergic Pathways in Drug-Induced Valvular Heart Disease and Diagnostic Features by Echocardiography. J Am Soc Echocardiogr. août 2009;22(8):883-9.

- This article with reference (39) specifies the pharmacological mechanism involved in iatrogenic fibrosis, in particular in the occurrence of cardiac valvulopathy.

28. Bullimore DW. Retroperitoneal fibrosis associated with metoprolol. Br Med J Clin Res Ed. 27 févr 1982;284(6316):664.

29. Laakso M, Arvala I, Tervonen S, et al. Retroperitoneal fibrosis associated with sotalol. Br Med J Clin Res Ed. 16 oct 1982;285(6348):1085-6.

30. Doherty CC, McGeown MG, Donaldson RA. Retroperitoneal fibrosis after treatment with atenolol. Br Med J. 23 déc 1978;2(6154):1786.

31. Pryor JP, Castle WM, Dukes DC, et al. Do beta-adrenoceptor blocking drugs cause retroperitoneal fibrosis? Br Med J Clin Res Ed. 3 sept 1983;287(6393):639-41.

- This is the first article questioning the causal role of beta-blockers in the occurrence of RPF.

32. Lewis CT, Molland EA, Marshall VR, et al. Analgesic abuse, ureteric obstruction, and retroperitoneal fibrosis. Br Med J. 12 avr 1975;2(5962):76-8.

33. Waters VV. Hydralazine, hydrochlorothiazide and ampicillin associated with retroperitoneal fibrosis: case report. J Urol. avr 1989;141(4):936-7.

34. Couderc M, Mathieu S, Dubost J-J, et al. Retroperitoneal Fibrosis During Etanercept Therapy for Rheumatoid Arthritis. J Rheumatol. nov 2013;40(11):1931-3. 
- This is the first case reported of RPF induced by TNF-alpha antagonist (etanercept) in literature supporting the hypothesis of a dysregulation of the immune system in the process of iatrogenic RPF.

35. Shiber S, Eliakim-Raz N, Yair M. Retroperitoneal fibrosis: case series of five patients and review of the literature. Rev Bras Reumatol. avr 2016;56(2):101-4.

36. Manganelli S, Giannitti C, Galeazzi M, et al. Retroperitoneal fibrosis following a long-standing etanercept treatment in a spondyloarthritis patient. Jt Bone Spine Rev Rhum. mai 2018;85(3):389-90.

37. Massara A, Cavazzini L, La Corte R, et al. Sarcoidosis Appearing During Anti-Tumor Necrosis Factor $\alpha$ Therapy: A New "Class Effect" Paradoxical Phenomenon. Two Case Reports and Literature Review. Semin Arthritis Rheum. févr 2010;39(4):313-9.

38. Catanoso MG, Spaggiari L, Magnani L, et al. Efficacy of infliximab in a patient with refractory idiopathic retroperitoneal fibrosis. Clin Exp Rheumatol. oct 2012;30(5):776-8.

39. Lapi F, Nicotra F, Scotti L, et al. Use of antidepressant serotoninergic medications and cardiac valvulopathy: a nested case-control study in the health improvement network (THIN) database: Cardiac valvulopathy and antidepressant serotoninergic medications. Br J Clin Pharmacol. sept 2012;74(3):536-44.

40. Graham JR. Methysergide for Prevention of Headache: Experience in Five Hundred Patients over Three Years. N Engl J Med. 9 janv 1964;270(2):67-72.

41. Utz DC. Retroperitoneal Fibrosis in Patients Taking Methysergide. JAMA J Am Med Assoc. 22 mars 1965;191(12):983.

42. Carr RJ, Biswas BK. Methysergide and retroperitoneal fibrosis. $\mathrm{Br}$ Med J. 5 nov 1966;2(5522):1116-7.

43. Seymour R. Retroperitoneal fibrosis associated with methysergide therapy for migraine. Med J Aust. 13 janv 1968;1(2):59-60.

44. Stecker JF, Rawls HP, Devine CJ, et al. Retroperitoneal fibrosis and ergot derivatives. J Urol. juill 1974;112(1):30-2.

45. Iversen BM, Johannesen JW, Nordahl E, et al. Retroperitoneal fibrosis during treatment with methydopa. Lancet Lond Engl. 16 août 1975;2(7929):302-4.

46. Johnson JN, McFarland J. Retroperitoneal fibrosis associated with stenolol. Br Med J. 22 mars 1980;280(6217):864.

47. Gavin MJ, Castle WM, Cruickshank JM, et al. Retroperitoneal fibrosis associated with atenolol. Br Med J. 17 mai 1980;280(6225):1227-8.

48. Rose FL, Bergel F. Retroperitoneal fibrosis associated with atenolol. Br Med J. 13 sept 1980;281(6242):745.

49. Bullimore DW. Retroperitoneal fibrosis associated with atenolol. Br Med J. 23 août 1980;281(6239):564.

50. McClusky DR, Donaldson RA, McGeown MG. Oxprenolol and retroperitoneal fibrosis. Br Med J. 29 nov 1980;281(6253):1459-60. 
51. Pierce JR, Trostle DC, Warner JJ. Propranolol and retroperitoneal fibrosis. Ann Intern Med. août 1981;95(2):244.

52. Henri L, Groleau M. Retroperitoneal fibrosis after treatment with propranolol. Drug Intell Clin Pharm. sept 1981;15(9):696.

53. Thompson J, Julian DG. Retroperitoneal fibrosis associated with metoprolol. Br Med J Clin Res Ed. 9 janv 1982;284(6309):83-4.

54. Bowler JV, Ormerod IE, Legg NJ. Retroperitoneal fibrosis and bromocriptine. Lancet Lond Engl. 23 août 1986;2(8504):466.

55. Ward CD, Thompson J, Humby MD. Pleuropulmonary and retroperitoneal fibrosis associated with bromocriptine treatment. J Neurol Neurosurg Psychiatry. déc 1987;50(12):1706-7.

56. Mitchinson MJ. Methysergide and retroperitoneal fibrosis. Lancet Lond Engl. 11 avr 1987;1(8537):870.

57. Reimund E. Methysergide and retroperitoneal fibrosis. Lancet Lond Engl. 21 févr 1987;1(8530):443.

58. Murphy F, Pickard RS. Bromocriptine-associated retroperitoneal fibrosis presenting with testicular retraction. Br J Urol. sept 1989;64(3):318-9.

59. Herzog A, Minne H, Ziegler R. Retroperitoneal fibrosis in a patient with macroprolactinoma treated with bromocriptine. BMJ. 13 mai 1989;298(6683):1315.

60. Vermersch P, Foissac-Gegoux P, Caron J, et al. [Retroperitoneal fibrosis after treatment with bromocriptine]. Presse Medicale Paris Fr 1983. 22 avr 1989;18(16):841.

61. Kaminsky P, Hirsch E, Kiesman M, et al. [Retroperitoneal fibrosis after treatment by bromocriptine]. Presse Medicale Paris Fr 1983. 15 avr 1989;18(15):777.

62. Ahmad S. Atenolol and retroperitoneal fibrosis. South Med J. nov 1990;83(11):1367.

63. Kains JP, Hardy JC, Chevalier C, et al. Retroperitoneal fibrosis in two patients with Parkinson's disease treated with bromocriptine. Acta Clin Belg. 1990;45(5):306-10.

64. Dupuis J, Bodnar D, Sturtz F, et al. [Reversible retroperitoneal fibrosis after prolonged treatment with bromocriptine: apropos of 2 cases]. Rev Med Interne. avr 1990;11(2):183.

65. Hely MA, Morris JG, Lawrence S, et al. Retroperitoneal fibrosis, skin and pleuropulmonary changes associated with bromocriptine therapy. Aust N Z J Med. févr 1991;21(1):82-4.

66. Adab FA, Mould JJ. Carboplatin and retroperitoneal fibrosis. Clin Oncol R Coll Radiol G B. sept 1992;4(5):327-8.

67. Jiménez-Jiménez FJ, López-Alvarez J, Sánchez-Chapado M, et al. Retroperitoneal fibrosis in a patient with Parkinson's disease treated with pergolide. Clin Neuropharmacol. juin 1995;18(3):277-9.

68. Ahmad S. Association of metoprolol and retroperitoneal fibrosis. Am Heart J. janv 1996;131(1):202-3.

69. Bucci JA, Manoharan A. Methysergide-induced retroperitoneal fibrosis: successful outcome and two new laboratory features. Mayo Clin Proc. déc 1997;72(12):1148-50. 
70. Kunkler RB, Osborn DE, Abbott RJ. Retroperitoneal fibrosis caused by treatment with pergolide in a patient with Parkinson's disease. Br J Urol. juill 1998;82(1):147.

71. Lund BC, Neiman RF, Perry PJ. Treatment of Parkinson's disease with ropinirole after pergolideinduced retroperitoneal fibrosis. Pharmacotherapy. déc 1999;19(12):1437-8.

72. Mondal BK, Suri S. Pergolide-induced retroperitoneal fibrosis. Int J Clin Pract. août 2000;54(6):403.

73. Agarwal P, Fahn S, Frucht SJ. Diagnosis and management of pergolide-induced fibrosis. Mov Disord Off J Mov Disord Soc. juin 2004;19(6):699-704.

74. Cai FZ, Tesar P, Klestov A. Methysergide-induced retroperitoneal fibrosis and pericardial effusion. Intern Med J. mai 2004;34(5):297-8.

75. Alvarez-Múgica M, Jalón Monzón A, Bulnes Vázquez V, et al. [Retroperitoneal fibrosis in relation to use of analgesics, tramadol and paracetamol]. Arch Esp Urol. nov 2006;59(9):923. 


\begin{tabular}{|c|c|c|c|c|c|c|c|}
\hline $\begin{array}{l}\text { Localization of fibrosis on imaging, } \\
\text { Circumstances of diagnostic, } N(\%)\end{array}$ & WP & UO & UO+FK & $\mathrm{UO}+\mathrm{H}$ & $M$ & AA & Total \\
\hline Isolated RF & $6(8.2)$ & $6(8.2)$ & $1(1.4)$ & $2(2.7)$ & $1(1.4)$ & $0(0)$ & 16 (21.9) \\
\hline Pain* & $16(21.9)$ & $4(5.5)$ & $0(0)$ & $0(0)$ & $0(0)$ & $1(1.4)$ & $21(28.8)$ \\
\hline RF and LLD & $1(1.4)$ & $2(2.7)$ & $0(0)$ & $0(0)$ & $0(0)$ & $0(0)$ & $3(4.1)$ \\
\hline RF and pain* & $0(0)$ & $2(2.7)$ & $0(0)$ & $0(0)$ & $0(0)$ & $0(0)$ & $2(2.7)$ \\
\hline NS & $14(19.2)$ & $2(2.7)$ & $0(0)$ & $1(1.4)$ & $0(0)$ & $0(0)$ & $17(23.3)$ \\
\hline Total & $47(64.4)$ & $18(24.7)$ & $1(1.4)$ & $5(6.8)$ & $1(1.4)$ & $1(1.4)$ & $73(100)$ \\
\hline Total RF (isolated or associated with pain or LLD) & $7(9.6)$ & $10(13.7)$ & $1(1.4)$ & $2(2.7)$ & $1(1.4)$ & $0(0)$ & $21(28.8)$ \\
\hline Total LLD (isolated or associated with pain or RF) & $7(9.6)$ & $2(2.7)$ & $0(0)$ & $2(2.7)$ & $0(0)$ & $0(0)$ & $11(15.1)$ \\
\hline Total 'pain' (isolated or associated with LLD or RF) & $17(23.3)$ & $6(8.2)$ & $0(0)$ & $1(1.4)$ & $0(0)$ & $1(1.4)$ & $25(34.2)$ \\
\hline
\end{tabular}

\section{RF: renal failure}

LLD: lower limb damage (edema or deep vein thrombosis)

*abdominal and/or low-back pain

FD: fortuitous diagnosis

NS: circumstances of diagnostic are not specified
WP: without particularities. RPF with involvement of abdominal aorta and/or vena cava and/or iliac arteries and/or renal arteries and/or mesenteric arteries without specific mention about involvement of urinary tract, kidneys or mediastinal zone or aortic aneurysm.

UO: ureteral obstruction

FK: fibrosis surrounding kidneys

H: hydronephrosis

M: involvement of mediastinal zone (without details)

AA: aortic aneurysm

Table 1: Circumstances of diagnostic and the localization of fibrosis on imaging $(n=73)$ 


\begin{tabular}{|c|c|c|c|c|}
\hline Therapeutic Class & $\begin{array}{l}\text { Number of RPF } \\
\text { in the FPVD }\end{array}$ & $\begin{array}{c}\text { Total number of } \\
\text { cases (all ADR } \\
\text { included) }\end{array}$ & ROR & $95 \% \mathrm{Cl}$ \\
\hline Beta blockers & 28 & 11446 & 38,8 & $(24.2,66.2)$ \\
\hline acebutolol & 3 & 1269 & 24,4 & $(7.7,77.7)$ \\
\hline atenolol & 5 & 1800 & 29,5 & $(11.9,73,3)$ \\
\hline betaxolol & 1 & 232 & 43,5 & $(6.0,314.0)$ \\
\hline bisoprolol & 9 & 3162 & 32,1 & $(16.0,64.6)$ \\
\hline celiprolol & 2 & 563 & 36,3 & $(8.9,148.2)$ \\
\hline metoprolol & 1 & 614 & 16,4 & $(2.3,118.0)$ \\
\hline nadolol & 1 & 153 & 66 & $(9.1,478.3)$ \\
\hline nebivolol & 1 & 912 & 11 & $(1.5,79.3)$ \\
\hline pindolol & 1 & 164 & 61,6 & $(8.5,445.8)$ \\
\hline propranolol & 3 & 1708 & 18,1 & $(5.7,57.6)$ \\
\hline sotalol & 1 & 869 & 11,6 & $(1.6,83,2)$ \\
\hline Diuretics & 11 & 27259 & 4,5 & $(2.4,8.6)$ \\
\hline loop diuretics & 1 & 9329 & 1,1 & $(0.1,7.6)$ \\
\hline furosemide & 1 & 9329 & 1,1 & $(0.1,7.6)$ \\
\hline potassium-sparing diuretics & 3 & 5595 & 5,5 & $(1.7,17.5)$ \\
\hline spironolactone & 2 & 5031 & 4 & $(1.0,16.4)$ \\
\hline triamterene & 1 & 564 & 17,8 & $(2.5,128.5)$ \\
\hline thiazide diuretics & 7 & 12335 & 6,1 & $(2.8,13.3)$ \\
\hline altizide & 2 & 1876 & 10,8 & $(2.7,44.2)$ \\
\hline clopamide & 1 & 26 & 401,6 & $(53.7,3003.7)$ \\
\hline cyclothiazide & 1 & 237 & 42,5 & $(5.9,307.3)$ \\
\hline hydrochlorothiazide & 2 & 7794 & 2,6 & $(0.6,10.5)$ \\
\hline indapamide & 1 & 2402 & 4,2 & $(0.6,30.0)$ \\
\hline Hypolipidemic drugs & 8 & 9706 & 9,1 & $(4.3,18.9)$ \\
\hline statin & 6 & 7480 & 8,6 & $(3.7,19.8)$ \\
\hline rosuvastatin & 2 & 1632 & 12,5 & $(3.1,50.9)$ \\
\hline fluvastatin & 1 & 524 & 19,2 & $(2.7,138.3)$ \\
\hline pravastatin & 1 & 2473 & 4 & $(0.6,29.1)$ \\
\hline simvastatin & 2 & 2851 & 7,1 & $(1.7,29.0)$ \\
\hline fibrate drugs & 1 & 2083 & 4,8 & $(0.7,34.6)$ \\
\hline fenofibrate & 1 & 2083 & 4,8 & $(0.7,34.6)$ \\
\hline other & 1 & 143 & 70,7 & $(9.8,512.2)$ \\
\hline cholestyramine & 1 & 143 & 70,7 & $(9.8,512.2)$ \\
\hline Agents acting on the renin-angiotensin system & 7 & 16458 & 4,6 & $(2.1,9.9)$ \\
\hline angiotensin II receptor antagonists & 3 & 6055 & 5,1 & $(1.6,16.1)$ \\
\hline irbesartan & 1 & 2182 & 4,6 & $(0.6,33.0)$ \\
\hline losartan & 1 & 1366 & 7,3 & $(1.0,52.9)$ \\
\hline valsartan & 1 & 2507 & 4 & $(0.6,28.7)$ \\
\hline angiotensin-converting-enzyme inhibitors & 4 & 10403 & 4 & $(1.4,10.9)$ \\
\hline ramipril & 1 & 3725 & 2,7 & $(0.4,19.3)$ \\
\hline perindopril & 2 & 3927 & 5,2 & $(1.3,21.0)$ \\
\hline enalapril & 1 & 2751 & 3,6 & $(0.5,26.2)$ \\
\hline
\end{tabular}




\begin{tabular}{|c|c|c|c|c|}
\hline Therapeutic Class & $\begin{array}{c}\text { Number of RPF } \\
\text { in the FPVD }\end{array}$ & $\begin{array}{l}\text { Total number of } \\
\text { cases (all ADR } \\
\text { included) }\end{array}$ & ROR & $95 \% \mathrm{Cl}$ \\
\hline Calcium antagonists & 3 & 10505 & 2,9 & $(0.9,9.2)$ \\
\hline nitrendipine & 1 & 5045 & 2 & $(0.3,14.2)$ \\
\hline amlodipine & 1 & 3527 & 2,8 & $(0.4,20.4)$ \\
\hline nicardipine & 1 & 1933 & 5,2 & $(0.7,37.3)$ \\
\hline Antiarrhythmic drugs & 2 & 4210 & 4,8 & $(1.2,19.6)$ \\
\hline amiodarone & 1 & 487 & 20,6 & $(2.9,148.9)$ \\
\hline digoxine & 1 & 3723 & 2,7 & $(0.4,19.3)$ \\
\hline Antipsychotic drugs & 7 & 12100 & 6,2 & $(2.9,13.6)$ \\
\hline haloperidol & 2 & 2610 & 7,8 & $(1.9,31.7)$ \\
\hline zuclopenthixol & 1 & 546 & 18,4 & $(2.6,132.7)$ \\
\hline cyamemazine & 1 & 3779 & 2,6 & $(0.4,19.0)$ \\
\hline levomepromazine & 1 & 1459 & 6,9 & $(1.0,49.5)$ \\
\hline risperidone & 1 & 3419 & 2,9 & $(0.4,21.0)$ \\
\hline pipamperone & 1 & 287 & 35,1 & $(4.9,253.4)$ \\
\hline Anxiolytic drugs & 6 & 9448 & 6,8 & $(2.9,15.6)$ \\
\hline bromazepam & 2 & 3847 & 5,3 & $(1.3,21.5)$ \\
\hline alprazolam & 2 & 3297 & 6,2 & $(1.5,25.1)$ \\
\hline meprobamate & 2 & 2304 & 8,8 & $(2.2,36.0)$ \\
\hline Hypnotic drugs & 8 & 8496 & 10,4 & $(5.0,21.6)$ \\
\hline aceprometazine & 2 & 1633 & 12,5 & $(3.1,50.8)$ \\
\hline zolpidem & 5 & 3771 & 14 & $(5.7,34.8)$ \\
\hline zopiclone & 1 & 3092 & 3,2 & $(0.4,23.3)$ \\
\hline Antimigraine drugs & 16 & 1576 & 129,8 & $(74.4,226.5)$ \\
\hline dihydroergotamine & 7 & 600 & 129,2 & $(59.0,282.7)$ \\
\hline ergotamine & 1 & 899 & 11,2 & $(1.6,80.4)$ \\
\hline methysergide & 8 & 77 & 1289,4 & $\begin{array}{r}(596.2, \\
2788.5) \\
\end{array}$ \\
\hline Antidepressants & 8 & 21315 & 4,1 & $(1.9,8.4)$ \\
\hline serotonin selective reuptake inhibitors & 3 & 10083 & 3 & $(1.0,9.6)$ \\
\hline sertraline & 1 & 1656 & 6,1 & $(0.8,43.6)$ \\
\hline fluoxetine & 1 & 3853 & 2,6 & $(0.4,18.7)$ \\
\hline paroxetine & 1 & 4574 & 2,2 & $(0.3,15.7)$ \\
\hline serotonin-norepinephrine reuptake inhibitors & 1 & 3100 & 3,2 & $(0.4,23.2)$ \\
\hline venlafaxine & 1 & 3100 & 3,2 & $(0.4,23.2)$ \\
\hline tricyclic antidepressant & 3 & 5712 & 5,4 & $(1.7,17.1)$ \\
\hline amitriptylline & 1 & 2701 & 3,7 & $(0.5,26.7)$ \\
\hline maprotiline & 1 & 431 & 23,3 & $(3.2,168.3)$ \\
\hline clomipramine & 1 & 2580 & 3,9 & $(0.5,27.9)$ \\
\hline other antidepressant & 1 & 2420 & 4,1 & $(0.6,29.8)$ \\
\hline mianserine & 1 & 2420 & 4,1 & $(0.6,29.8)$ \\
\hline Antiepileptic drugs & 5 & 6813 & 7,7 & $(3.1,19.2)$ \\
\hline valproic acid & 4 & 4274 & 9,8 & $(3.6,26.7)$ \\
\hline lamotrigine & 1 & 2539 & 3,9 & $(0.5,28.4)$ \\
\hline
\end{tabular}




\begin{tabular}{|c|c|c|c|c|}
\hline Therapeutic Class & $\begin{array}{c}\text { Number of RPF } \\
\text { in the FPVD }\end{array}$ & $\begin{array}{l}\text { Total number of } \\
\text { cases (all ADR } \\
\text { included) }\end{array}$ & ROR & $95 \% \mathrm{Cl}$ \\
\hline Antiparkinsonian drugs & 3 & 3440 & 9 & $(2.8,28.5)$ \\
\hline trihexyphenidyl & 1 & 944 & 10,6 & $(1.5,76.6)$ \\
\hline pergolide & 1 & 194 & 52 & $(7.2,376.2)$ \\
\hline levodopa, carbidopa & 1 & 2302 & 4,3 & $(0.6,31.3)$ \\
\hline Inhibitors of prolactin secretion & 4 & 1148 & 36,6 & $(13.3,100.4)$ \\
\hline cabergoline & 1 & 143 & 70,7 & $(9.8,512.2)$ \\
\hline bromocriptine & 3 & 1005 & 30,9 & $(9.7,98.2)$ \\
\hline Non-steroidal anti-inflammatory drugs & 4 & 13931 & 3 & $(1.1,8.1)$ \\
\hline diclofenac & 1 & 4532 & 2,2 & $(0.3,15.9)$ \\
\hline celecoxib & 1 & 1528 & 6,6 & $(0.9,47.3)$ \\
\hline ibuprofen & 1 & 6744 & 1,5 & $(0.2,10.6)$ \\
\hline glafenine & 1 & 1127 & 8,9 & $(1.2,64.1)$ \\
\hline Analgesics (except anti-inflammatory) & 2 & 32826 & 0,6 & $(0.15,2.41)$ \\
\hline tramadol & 1 & 8383 & 1,2 & $(0.2,8.5)$ \\
\hline acetaminophen & 1 & 24443 & 0,4 & $(0.1,2.9)$ \\
\hline Antidiabetic drugs & 6 & 18129 & 3,5 & $(1.5,8.0)$ \\
\hline benfluorex & 2 & 12002 & 1,7 & $(0.4,6.8)$ \\
\hline gliclazide & 1 & 1445 & 6,9 & $(1.0,50.0)$ \\
\hline metformine & 3 & 4682 & 6,6 & $(2.1,20.9)$ \\
\hline Platelet antiaggregants & 7 & 8294 & 9,1 & $(4.2,19.9)$ \\
\hline ticlopidine & 1 & 1573 & 6,4 & $(0.9,45.9)$ \\
\hline aspirin & 5 & 6183 & 8,5 & $(3.4,21.2)$ \\
\hline dipyridamole & 1 & 538 & 18,7 & $(2.6,134.7)$ \\
\hline TNF- $\alpha$ antagonist & 4 & 4614 & 9 & $(3.3,24.8)$ \\
\hline adalimumab & 2 & 2507 & 8,1 & $(2.0,33.0)$ \\
\hline etanercept & 2 & 2107 & 9,6 & $(2.4,39.4)$ \\
\hline Platinum salts & 2 & 6493 & 3,1 & $(0.8,12.7)$ \\
\hline carboplatin & 1 & 3372 & 3 & $(0.4,21.3)$ \\
\hline cisplatin & 1 & 3121 & 3,2 & $(0.4,23.1)$ \\
\hline Antihistamines drugs & 2 & 1763 & 11,5 & $(2.8,47.1)$ \\
\hline alimemazine & 1 & 1567 & 6,4 & $(0.9,46.1)$ \\
\hline doxylamine & 1 & 196 & 51,5 & $(7.1,372.3)$ \\
\hline Proton pump inhibitors & 2 & 15083 & 1,3 & $(0.3,5.4)$ \\
\hline omeprazole & 1 & 10180 & 1 & $(0.1,7.0)$ \\
\hline esomeprazole & 1 & 4903 & 2 & $(0.3,14.6)$ \\
\hline
\end{tabular}




\begin{tabular}{|c|c|c|c|c|}
\hline Therapeutic Class & $\begin{array}{l}\text { Number of RPF } \\
\text { in the FPVD }\end{array}$ & $\begin{array}{l}\text { Total number of } \\
\text { cases } \\
\text { (all ADR included) }\end{array}$ & ROR & $95 \% \mathrm{Cl}$ \\
\hline Other drugs & 31 & & & \\
\hline timolol eye drop & 3 & 726 & 42,8 & $(13.4,136.3)$ \\
\hline levothyroxine & 2 & 27616 & 0,7 & $(0.2,2.9)$ \\
\hline ferrous sulfate & 2 & 1576 & 12.9 & $(3.2,52.7)$ \\
\hline alendronate & 1 & & & \\
\hline alfuzosin & 1 & & & \\
\hline allopurinol & 1 & & & \\
\hline avocado soy unsaponifiables & 1 & & & \\
\hline caffeine & 1 & & & \\
\hline clobenzorex & 1 & & & \\
\hline finasteride & 1 & & & \\
\hline fluindione & 1 & & & \\
\hline fluorouracil & 1 & & & \\
\hline horse chestnut extract & 1 & & & \\
\hline insulin & 1 & & & \\
\hline interferon B1b & 1 & & & \\
\hline latanoprost eye drop & 1 & & & \\
\hline memantine & 1 & & & \\
\hline oxymetazoline & 1 & & & \\
\hline paclitaxel & 1 & & & \\
\hline pentaerythrityl & 1 & & & \\
\hline permethol & 1 & & & \\
\hline ponatinib & 1 & & & \\
\hline tamsulosin & 1 & & & \\
\hline travoprost eye drop & 1 & & & \\
\hline trimebutine & 1 & & & \\
\hline sibutramine & 1 & & & \\
\hline yohimbine & 1 & & & \\
\hline Total & 176 & & & \\
\hline DEA* & 21 & 2918 & 100,4 & $(60.4,166.8)$ \\
\hline benzodiazepines or benzodiazepine-like agents $* *$ & 10 & 14007 & 8 & $(4.1,15.7)$ \\
\hline
\end{tabular}

*cabergoline $n=1$, bromocriptine $n=3$, pergolide $n=1$, dihydroergotamine $n=7$, ergotamine $n=1$, methysergide $n=8$

** bromazepam $n=2$, alprazolam $n=2$, zolpidem $n=5$, zopiclone $n=1$

ROR was not calculated when $\mathrm{N}=1$ and no possibility of grouping by pharmacological class.

Disproportionality signals appear in bold.

Table 2: Risk of exposure to drugs in cases ( $n=73$ with 176 suspect drugs) and noncases $(n=722867)$ and occurrence of RPF in the French PharmacoVigilance Database (FPVD) 